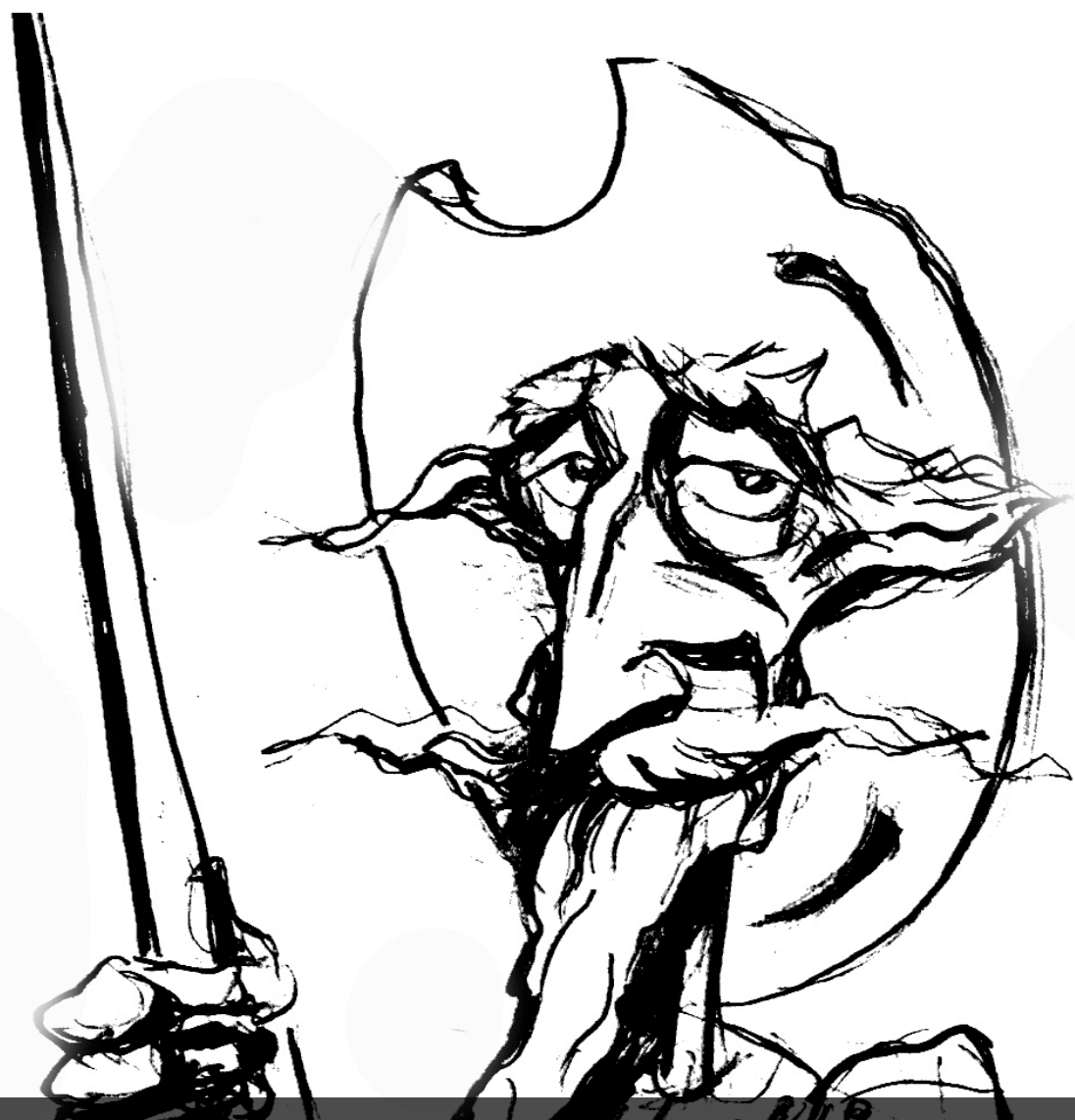

Sentidos de lo político: una aproximación a las memorias militantes de la ciudad de Bahía Blanca.

[Gabriela González] 


\title{
Sentidos de lo político: una aproximación a las memorias militantes de la ciudad de Bahía Blanca.
}

\author{
Senses of the political: An approach to the militant memories of the city of \\ Bahia Blanca.
}

GABRIELA GONZÁLEZ

\section{Resumen}

En este trabajo nos proponemos analizar, desde una mirada antropológica, cómo la reformulación de la militancia política peronista de los años setenta, con foco en la ciudad de Bahía Blanca, se proyecta hacia la militancia política durante los gobiernos kirchneristas. Se contempla particularmente la valoración que sujetos pertenecientes a la denominada generación del setenta enuncian en términos de continuidades y rupturas entre su militancia pasada y la militancia política de las nuevas generaciones. Se procura así dar cuenta de aquellos elementos que hoy entran en tensión a cerca de la militancia en Bahía Blanca y de las distintas interpretaciones, a través de las cuales la política es caracterizada.

Palabras claves: memoria - política - militancia generación - Bahía Blanca

\begin{abstract}
In this paper we analyze, from an anthropological view, how the reformulation of the Peronist political militancy of the seventies is projected toward the Kirchner's governments, focusing on the city of Bahía Blanca. It is particularly contemplated the assessment that the subjects belonging to the so-called generation seventy enunciate in terms of continuities and ruptures between his past militancy and the political militancy of the new generations. Thus, we intend to give an account of those elements which are in tension today about militancy in Bahia Blanca, as well as the different interpretations, through which politics is characterized.
\end{abstract}

Keywords: memory - politics - militancy generation - Bahía Blanca

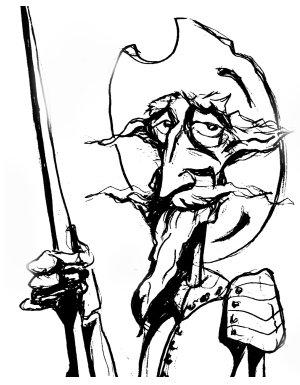

Recibido con pedido de publicación el 8 de abril de 2016 Aceptado para su publicación el 19 de octubre de 2016 Versión definitiva recibida el 15 de noviembre de 2016

Gabriela González, Instituto Rosario de Investigación en Ciencias de la Educación, Consejo Nacional de Investigaciones Científicas y Técnicas, Argentina; e-mail: gonzalez@irice-conicet.gov.ar 


\section{A modo de introducción}

Esta investigación ${ }^{1}$ estuvo orientada desde un enfoque antropológico, a partir del cual procuramos realizar un abordaje relacional de los procesos sociales y cotidianos en torno a la militancia política peronista. Dentro de esta perspectiva el énfasis se halla puesto en la consideración de que la perspectiva de los sujetos y sus experiencias devienen en un camino privilegiado para acceder al conocimiento del mundo social. ${ }^{2}$ Esta consideración no implica una reducción del análisis antropológico a meras opciones de sentido común, o a una homogenización o naturalización de las diferencias entre los sujetos. ${ }^{3}$ Por el contrario, en tanto sujetos históricamente situados, dichas perspectivas se entrelazan en una trama de relaciones sociales y políticas que pueden ser comprendidas por medio de una mirada antropológica.

Buscamos, de esta manera, abordar relacionalmente la militancia peronista bahiense en la década del setenta y la militancia política durante los gobiernos kirchneristas. Para ello recurrimos principalmente a testimonios de ex militantes peronistas, en tanto herramienta metodológica particular. Esta opción retoma algunos de los planteos de Pilar Calveiro, para quien el testimonio -en el caso argentino- constituye una práctica signada políticamente y direccionada de manera específica. De ahí que este posea una "valencia política", es decir, un lugar significativo en la "construcción de la historia del terrorismo de Estado, como relato de verdad socialmente validado". ${ }^{4}$

Si bien este posicionamiento respecto de la recuperación de la experiencia del sujeto militante, por medio del relato testimonial, nos habla de unas memorias entendidas inicialmente como relatos transmitidos por "aquellos que lo vivieron", no pretendemos generar un relato petrificado, inmóvil, siempre igual a sí mismo. Destacamos entonces la dimensión temporal que atraviesa a toda experiencia y su narración, dimensión que, por otro lado, encerraría una serie de problemas teóricos y metodológicos. En este sentido, algunos autores confieren a los testimonios el valor de fuente histórica, sin dejar

\footnotetext{
${ }^{1}$ El presente trabajo forma parte del proceso de investigación en el transcurso de nuestro doctorado en Humanidades con mención en Antropología. El mismo se realizó en el marco de una beca doctoral de Conicet, en la ciudad de Bahía Blanca entre 2010 y 2014.

2 BALBI, Fernando y BOIBIN, Mauricio "La perspectiva etnográfica en los estudios sobre política, Estado y gobierno", en Cuadernos de Antropología Social, núm. 27, Buenos Aires, 2008, pp. 7-17. DAS, Veena y POOLE, Deborah "El estado en sus márgenes. Etnografías comparadas", en Cuadernos de Antropología Social, Buenos Aires, 2008, pp. 19-52.

${ }^{3}$ GRIMBERG, Mabel "Poder, políticas y vida cotidiana. Un estudio antropológico sobre protesta y resistencia social en el Área Metropolitana de Buenos Aires", en Revista De Sociologia E Politica, Vol. 17, núm. 32, Curitiba, 2009, pp. 83-94.

${ }^{4}$ CALVEIRO, Pilar "Testimonio y memoria en el relato histórico", en Acta poética, Vol. 27, núm. 2, México, 2006, p. 65.
} 
de lado por ello los aspectos ético-políticos que hacen a su producción e interpretación. ${ }^{5}$ Otros, como Pollak y Heinich, ${ }^{6}$ consideran a los mismos como una fuente de la que habría que diferenciar la necesidad a la cual responde (testimonios judiciales, relatos autobiográficos, relatos históricos). Dado que nuestro interés en este trabajo no es el de focalizar en estas discusiones, quisiéramos subrayar, siguiendo a Oberti, ${ }^{7}$ que los testimonios y perspectivas de los sujetos en tornos a sus experiencias, en este caso de militancia, constituyen una herramienta válida como "estrategia de representación" que otorga sentido a la trayectoria de vida de aquel que narra, y nos permite aproximarnos al pasado de una manera particular.

En términos de ubicar los testimonios que fuéramos recogiendo a lo largo de nuestro trabajo de campo entre los años 2010 y 2014, consideramos necesario poder situar los mismos en su contexto singular. De este modo, al aproximarnos a las memorias militantes de Bahía Blanca, la referencia a la fuerte presencia de las Fuerzas Armadas durante la década del setenta aparece como una cita casi inevitable al momento de caracterizar la ciudad. Se trata de una presencia que muchos ubican desde su fundación, como fuerte de avanzada contra las tierras ocupadas por indígenas al sur del territorio argentino, hasta finales del siglo XIX y gran parte de siglo XX. Durante este último siglo, tal presencia se destacará por la participación que las Fuerzas Armadas tuvieran en los distintos golpes de Estado, en conjunto con otros sectores de poder del orden nacional y local, y por la influencia en la vida cotidiana de muchos bahienses. En este sentido cabe destacar, entre otros, el rol que ocupó en la ciudad La Nueva Provincia, ${ }^{8}$ la Iglesia Católica, el V Cuerpo de Ejército y la Base Naval Puerto Belgrano. ${ }^{9}$

${ }^{5}$ CARNOVALE, Vera; LORENZ, Federico y PITTALUGA, Roberto (comps.) Historia, memoria y fuentes orales, Memoria Abierta-Cedinci, Buenos Aires, 2006.

6 POLLAK, Michael y HEINICH, Natalie "El testimonio", en Actas de la investigación en Ciencias Sociales, núm. 62/63, 1986.

7 OBERTI, Alejandra "Contarse a sí mismas. La dimensión biográfica en los relatos de mujeres que participaron en las organizaciones político-militares de los '70", en CARNOVALE, Lorenz y PITTALUGA, Roberto (comps.) Historia, memoria y fuentes orales, Memoria Abierta-Cedinci, Buenos Aires, 2006, pp. 45-62.

${ }^{8}$ La Nueva Provincia es el mayor medio de comunicación de la ciudad de Bahía Blanca y la región, ampliamente destacado por su cercanía a los sectores más reaccionarios del país, entre ellos las Fuerzas Armadas, y por su fuerte sentimiento antiperonista. Para una lectura más profunda ver ZAPATA, Belén Páginas Manchadas. Conflictividad laboral entre los gráficos y La Nueva Provincia en vísperas de la dictadura de 1976, Tesis de Licenciatura en Historia, Universidad Nacional del Sur, Bahía Blanca, 2007; ZAPATA, Belén "Vigilados. La inteligencia bahiense sobre trabajadores y activistas sindicales (1973-1976)", en CERNADAS, Mabel y MARCILESE, José (eds.) Política, Sociedad y Cultura en el Sudoeste Bonaerense, EdiUNS, Bahía Blanca, 2009, pp. 139149; ZAPATA, Belén "Prensa y conflictividad laboral en Bahía Blanca. Problemáticas frente a la reconstrucción del pasado reciente en tres colectivos de trabajadores: estibadores, metalúrgicos y gráficos (1966-1976)", en CERNADAS, Mabel y ORBE, Patricia (comps.) Itinerarios de la prensa. 
Ahora bien, la influencia de las Fuerzas Armadas sobre el conjunto de la sociedad bahiense y sus alrededores no se reduce a la mera representación de estas en la ciudad. Por el contrario, es la vigilancia permanente, su autoridad y su presencia en diversos ámbitos de la vida cotidiana lo que ha permeado y configurado tanto imaginarios como trayectorias individuales de una manera significativa. De igual manera, las memorias sobre el pasado reciente se encuentran atravesadas por esta caracterización. En este sentido, nos hallamos con diversos testimonios que enfatizan en la estrecha relación entre estas y los aconteceres de la vida misma en Bahía Blanca, ya sea por lazos laborales, por haber cursado con docentes provenientes de la marina, por compartir ciertos espacios de concurrencia como clubes, por tener algún familiar, amigo y/o vecino perteneciente a la armada, al ejército o los restantes elementos militares presentes en la ciudad. Presencia que, además, imprimió a la militancia pasada ciertas singularidades.

"Había una profusa presencia en todos los barrios de las Fuerzas Armadas, con lo que supone esa ideología y esa transmisión que destila su ideología y el control y la sensación de ciudad vigilada y por otro lado, ideológicamente lo comunicativo y la iglesia como 'reserva moral de la sociedad' [...] Teníamos vecinos militares, o del Ejército, la Marina. La Marina tenía una influencia mayor a nivel cultural, le regalaba banderas a las escuelas, iba, llevaba la banda militar para que cantáramos el himno nacional, etc. Todos teníamos algún vecino, o hermano de una novia, o alguien que tenía que ver con los militares, o sea, mucha gente estaba asociada de alguna forma al ambiente militar" (Carlos). ${ }^{10}$

"Yo iba a la escuela fábrica en frente de la plaza Rivadavia y todos los profesores eran zumbos de Marina, eran todos suboficiales de Marina los profesores nuestros, entonces cómo ibas a hablar, qué ibas a hablar. Los profesores del Goyena, o del Nacional, eran todos profesores de los

Cultura política y representaciones en Bahía Blanca durante el siglo XX, EdiUNS, Bahía Blanca, 2013, pp. 249-271.

${ }_{9}$ La Base Naval Puerto General Belgrano se encuentra emplazada en la ciudad de Punta Alta, a $25 \mathrm{~km}$. de Bahía Blanca. La misma fue creada en 1898 en tierras en ese entonces pertenecientes al Partido de Bahía Blanca. Tras el golpe de 1955, de las instalaciones de la Base Aeronaval Comandante Espora, dependiente de Puerto Belgrano, despegaron algunos de los aviones que bombardearon la Plaza de Mayo.

${ }^{10}$ Carlos vive en Capital Federal y a comienzos de la década del setenta militó en Bahía Blanca en el PB (Peronismo de Base). Hasta el 2013 participaba en algunos organismos de derechos humanos. Entrevista realizada en agosto de 2013. 
sectores acomodados bahienses, esos tipos iban a dar la historia oficial. En cada barrio si no tenías un agente de Policía, tenías un suboficial del Ejército, o tenías un suboficial de Marina" (Esteban). ${ }^{11}$

"Cuando yo era chico, no hace tanto, íbamos en el colectivo y subía un guardiamarina, el cabo se tenía que parar y dejarle el asiento y si no iba en cana. Entraba al hospital naval un capitán de navío con resfrío y entraba un cabo con apendicitis, se podía morir de apendicitis que primero iba el capitán y esas cosas hay que seguir rompiéndolas, pero evidentemente es como un lugar intocable [...]. Dos chicos por patear un penal y decir -¿quién lo patea, tu papá qué es? -capitán de navío -entonces patea vos porque el mío es capitán de corbeta" (César). ${ }^{12}$

Si bien la mayoría de los registros refieren principalmente a la década del sesenta y setenta, algunos plantean una continuidad que llegaría hasta el presente, siguiendo la descripción realizada por César. Dicha continuidad llama la atención si la inscribimos en un contexto mayor, en el que lo concerniente a la participación de las Fuerzas Armadas en la última dictadura militar ha sido ampliamente puesto en escena. Se trata de un contexto histórico-político a nivel nacional en el cual la problemática de la memoria se transformó, desde 2004, en una política de Estado, con todos sus matices y los conflictos que ello conlleva. A partir de allí se habría reinaugurado la recuperación simbólica, antes nunca evocada desde el discurso presidencial, de los denominados "años setenta". Propiciando así una valorización de lo que fuera la "maravillosa juventud" militante de la década del setenta, en estrecha vinculación con los reclamos en materia de defensa de los derechos humanos y juzgamiento a militares y civiles que participaron del último golpe de Estado. El tratamiento de estas problemáticas devino así en profundos debates que incorporan tanto a intelectuales, como a diversos organismos de derechos humanos, funcionarios, militantes sociales y amplios sectores de la sociedad. ${ }^{13}$ En este punto cabría

${ }^{11}$ Esteban es arquitecto, vive en La Plata y a principios de los setenta militó en la JP de Bahía Blanca, siendo uno de los referentes de la Unidad Básica Evita Montonera de Ingeniero White. Entrevista realizada en agosto de 2013. En la actualidad no milita en ningún espacio orgánico, aunque tiene una participación activa en distintos ámbitos.

${ }^{12}$ César vive en Capital Federal y participa de diversos espacios vinculados a organismos de derechos humanos. En la década del setenta militó en la Unión de Estudiantes Secundarios (UES) de la ciudad de Punta Alta. Registro de campo agosto de 2014.

13 GONZÁLEZ, Gabriela y SILVA, María Luz “Un acercamiento antropológico a las memorias del pasado reciente en Argentina. El caso de la militancia peronista en los años setenta", en Gazeta de Antropología, Vol. 27, núm. 1, Jaén, 2011 [en línea]. Dirección URL: http://www.gazetaantropologia.es/?p=1353, acceso 23 de febrero de 2014. 
mencionar que la ciudad de Bahía Blanca no se mantuvo ajena a lo acontecido en el orden nacional, mientras que en el caso de Punta Alta, ciudad vecina y enclave de la Base Naval de Puerto Belgrano, dicho proceso de memorialización no fue acompañado de igual modo por gran parte de la comunidad como del gobierno local.

Por otro lado, los conflictos que fueron emergiendo en esta nueva configuración político-social pusieron en escena viejas y nuevas miradas acerca de cómo pensar la década del setenta, ya sea en términos crítico-políticos para algunos, ya en términos de idealización para otros. ${ }^{14}$ Del mismo modo, la politización de diversos sectores sociales, entre ellos sectores de juventud, ha generado importantes controversias cuyo anclaje con la década en cuestión ha sido determinante. Controversias que indican diversas memorias construidas desde el presente sobre aquel paradigmático pasado y que, a su vez, enuncian complejidades, heterogeneidades y conflictos pretéritos y contemporáneos, tanto en el plano de las representaciones como en el de las prácticas políticas actuales. Respecto de Bahía Blanca, esta apertura nos permitió adentrarnos en una problemática que hasta entrado el siglo XXI había permanecido en gran medida invisibilizada. Cabe destacar entre los diversos intentos por abordar esta problemática, los trabajos de investigación desarrollados en el marco de la carrera de historia de la UNS, ${ }^{15}$ la cátedra libre de Derechos Humanos de la mencionada Universidad y las distintas actividades sostenidas por organismos de Derechos Humanos de la ciudad.

\footnotetext{
${ }^{14}$ PASTORIZA, Lila "Hablar de memorias en Argentina", en VINYES, Ricard (comp.) El Estado y la memoria, RBA, Buenos Aires, 2009, pp. 291-329.

${ }^{15}$ DOMINELLA, Virginia El fermento en la masa. La Juventud Universitaria Católica en Bahía Blanca, entre la efervescencia política y la oleada represiva de la Triple A 1968-1975, Tesina de Licenciatura, Universidad Nacional del Sur, Bahía Blanca, 2010. JENSEN, Silvina "Diálogos entre la Historia Local y la Historia Reciente en Argentina. Bahía Blanca durante la última dictadura militar", en XIV Encuentro de Latinoamericanistas Españoles, Universidade de Santiago de Compostela, Centro Interdisciplinario de Estudios Americanistas Gumersindo Busto; Consejo Español de Estudios Iberoamericanos, Cursos e Congresos; 196, 2010, pp. 1426-1447. GIMÉNEZ, María Julia Ciudad de "perros". Historias de militancia y recorridos del PRT-ERP por la ciudad de Bahía Blanca, Tesina de grado, Universidad Nacional del Sur, Bahía Blanca, 2008. ORBE, Patricia “De la radicalización política a la partidización de los claustros: el caso de la comunidad universitaria de Bahía Blanca a comienzos de la década de los setenta", 2008. Disponible en http://iigg.sociales.uba.ar/files/2011/06/elatina24.pdf. RODRÍGUEZ, Andrea "La memoria naval de Malvinas. De olvidos, silencios y jerarquizaciones de experiencias", en X Jornadas de Sociología, Facultad de Ciencias Sociales - Universidad de Buenos Aires, Buenos Aires, 2013. Disponible en http://www.aacademica.com/000-038/253.pdf. VIDAL, Ana María “Arte y memoria colectiva. Representaciones de la militancia política y la represión de la década del '70 en Bahía Blanca (Argentina), 1995-2009", 2009. Disponible en http://www.academia.edu/4338324/Arte_y_memoria_colectiva._Representaciones_de_la_milita ncia_pol\%C3\%ADtica_y_la_represi\%C3\%B3n_de_la_d\%C3\%A9cada_del_70_en_Bah\%C3\%AD a_Blanca_Argentina_1995-2009. ZAPATA, Belén Páginas Manchadas..., cit.
} 
En este sentido, nuestra inquietud remite a cómo nos aproximamos a las experiencias militantes, desde los sentidos que el sujeto militante de "los años setenta" recrea en el presente sobre sus propias vivencias, en comparación con las actuales prácticas y acontecimientos políticos. Para ellos nos centramos en la memoria como una categoría en movimiento, ${ }^{16}$ en tanto una de sus características centrales es la posibilidad de vincular el pasado con el presente y el futuro. En otras palabras, se trata de comprender el presente desde el cual se reconstruye ese pasado, a partir de repreguntarse por los atravesamientos, los errores para algunos, los aciertos para otros, los aprendizajes y sus sentidos en el momento actual.

\section{Memoria y transmisión}

En este intento por relacionar un tiempo y otro, en las memorias en torno a la militancia fue haciéndose cada vez más visible una de las dimensiones que la caracterizan, la afectiva. Dimensión que fue cobrando fuerza a partir de la transmisión de la experiencia política vivida, desde aquel lugar de intimidad ya no pensado sino sentido o en el que pensar y sentir se entrelazan íntimamente en cada testimonio, provenga este de una entrevista o de una observación de la cual participáramos. De todos modos, cabe señalar que a lo largo de todo este proceso de investigación nos encontramos con no pocas dificultades a la hora de poder abordar las memorias bahienses, dado que muchos de los militantes de aquellos años fueron, o bien asesinados y/o desaparecidos, o bien se exiliaron, o bien preferían no volver sobre las experiencias pasadas, o hacer de vínculo con otros compañeros a los que sí les podría interesar transmitir su experiencia.

A pesar de las limitaciones especificadas, los testimonios relevados nos permitieron construir un relato determinado acerca del pasado reciente y del presente, a partir de los sentidos que cada sujeto le atribuyó a dicho pasado y presente. Si bien consideramos que cada uno de ellos constituye un testimonio único e irrepetible, al mismo tiempo sostenemos que, a partir de esa singularidad, podemos aproximarnos a las memorias colectivas y culturales ${ }^{17}$ en términos de proceso. De esta manera recogimos diversos testimonios de sujetos que durante su juventud optaron por la militancia política, especialmente en la Juventud Peronista, pero sin particularizar en un solo ámbito, como podría ser la Juventud Universitaria Peronista (JUP), la Juventud Trabajadora Peronista (JTP) o el ámbito barrial o territorial. También tuvimos en cuenta la diferenciación en lo enunciado entre quienes continúan o no militando en la

\footnotetext{
16 CALVEIRO, Pilar "Testimonio y memoria...", cit.

17 BIANCHI, Silvia (ed.) "El Pozo". Un centro clandestino de detención, desaparición, tortura y muerte de personas de la ciudad de Rosario, Argentina. Antropología política del pasado reciente, Prohistoria, Rosario, 2009.
} 
actualidad. Esta consideración parte del supuesto de que, en la construcción narrativa presente de la experiencia particular del sujeto, podemos encontrar líneas de continuidad y ruptura en cuanto a las formas de construcción y de concepciones políticas que difieren según se trate de un sujeto que continúa militando en el presente en espacios políticos y gremiales, o de un sujeto que haya elegido no hacerlo. Algo similar ocurre respecto de quienes continuaron viviendo en la ciudad de Bahía Blanca y de aquellos sujetos que tuvieron que exiliarse internamente o fuera del país, mediada esta diferencia por la caracterización en torno a la ciudad antes mencionada.

De acuerdo con las diferencias consideradas, en el análisis de dichos testimonios tuvimos en cuenta no solo cómo la memoria es construida hoy por los sujetos, en términos de un posicionamiento más o menos crítico, sino también los lugares de enunciación de cada uno, los recuerdos, los olvidos, las maneras de elaborar y transmitir lo acontecido, los vínculos y cómo el escenario etnográfico es construido.

En gran medida, en los diversos testimonios recabados, los años de militancia previos al golpe de Estado de 1976 aparecían definidos en términos de "el momento más alegre de mi vida", más allá de sus consecuencias trágicas o de las dificultades propias de aquel momento. "Era una cosa festiva, que de alguna manera nos afirmaba dentro de una especie de nosotros, nosotros los jóvenes que queremos pensar y que queremos actuar y que queremos construir un mundo mejor" (Carlos). "El momento más alegre" -de más está decirlo- era el tiempo de la militancia, de la vida como militancia, aún con las contradicciones y los conflictos que suscitaban la pertenencia a una estructura organizacional rígida.

Aún hoy, a cuarenta años de aquellas experiencias, las preguntas en torno "al momento más alegre de mi vida" no hablarían sino de la relación tensional vida/muerte puesta en juego a partir de la práctica política militante. Una práctica política que, por ende, representaría una forma de ser, estar y concebir el mundo. En este mismo sentido, cabe destacar algunas expresiones que aludían de manera directa a estas concepciones: "la vida por Perón", "Patria o muerte", la misma frase de "Hasta la victoria siempre", que luego de la muerte de Juan Domingo Perón pasó a ser "hasta la victoria, mi General". Frases todas ellas que contenían el binomio vida/muerte y que, en los testimonios por nosotros recogidos, aparecían reflejadas por medio de expresiones como: "no teníamos nada más que arriesgarnos en la vida" (Ricardo) ${ }^{18} \mathrm{o}$ "teníamos valores por los cuales dábamos la vida" (Marcelo). ${ }^{19} \mathrm{La}$

\footnotetext{
${ }^{18}$ Ricardo es jubilado, vive en Bahía Blanca y comenzó su militancia a mediados de los sesenta en la UOCRA y más tarde en la JTP (Juventud Trabajadora Peronista). En los setenta fue delegado de la JP de la regional sur por Bahía Blanca. Hasta el 2013 no militaba en ningún espacio orgánico. Entrevista realizada en febrero de 2011.

${ }_{19}$ Marcelo es docente y presidente hasta la actualidad del Mo.Ve.Ju.PA (Movimiento por la
} 
ausencia de interpretación de estas concepciones aparece mediada por la cuestión generacional, entendida esta como el conjunto de características determinadas compartidas en un momento dado. ${ }^{20}$ De este modo, aquel rasgo común de la autodenominada generación del setenta que refiere a la participación política en términos de vida/muerte, es presentado como un elemento de ruptura respecto de las nuevas generaciones militantes, a las que se les atribuirá características propias, incluso opuestas. Sobre estas continuidades y rupturas planteadas en clave generacional nos detendremos más adelante, sin embargo, quisiéramos por el momento relacionar estas concepciones nativas con la caracterización dada por María Inés Mudrovcic acerca de lo que esta autora denomina como "solapamiento generacional". Para Mudrovcic, "en todo presente coexisten, articuladas, varias generaciones y las relaciones que entre ellas se establecen constituyen la realidad de ese presente histórico", ${ }^{21}$ conformado además por las continuidades y discontinuidades propias de todo proceso histórico.

Retomando los atravesamientos en torno a la militancia pasada, el conjunto de estos argumentos, así como otros elementos que fuimos incorporando al análisis, nos permitió dar cuenta de cómo se habría dado la opción que muchos sujetos hicieron por la militancia política, incluso en las décadas previas a 1970. De esta manera, más que por su origen (la pérdida de las conquistas logradas por los trabajadores, la represión desatada por cada gobierno de facto, las diversas políticas implementadas por los gobiernos dictatoriales, etc.), tal opción pasó a estar determinada por los lazos sociales establecidos entre aquellos que vieron en el peronismo la posibilidad de conformar una identidad particular -de clase dirían algunos-, con sus valores, con su doctrina, sus banderas, su proyecto y con toda una red de vínculos $\mathrm{y}$ solidaridades fuertemente arraigadas. Se trata, por otro lado, de elementos que aún hoy conllevan una trascendencia significativa, en la medida en que los mismos son puestos en tensión a través del análisis de la práctica política de las nuevas generaciones. En tanto las opciones por la militancia en algún ámbito político estarían dadas por otros factores motivacionales. Aun así, el tema de las "herencias históricas" aparece siempre como un elemento que busca religar un tiempo y el otro, principalmente en el marco del peronismo que es en el que nos hemos centrado. Herencias que, por otro lado, nos hablan de una transmisión, ya como repetición, ya como transformación. Entramos entonces, nuevamente, en el terreno de la memoria.

Verdad y la Justicia de Punta Alta), a comienzo de los setenta tuvo una militancia gremial dentro del peronismo. Entrevista realizada en febrero de 2011.

${ }^{20}$ MARGULIS, Mario (ed.) La juventud es más que una palabra. Ensayos sobre cultura y juventud, Biblos, Buenos Aires, 2008.

${ }^{21}$ MUDROVCIC, María Inés Historia, narración y memoria. Los debates actuales en filosofía de la historia, Akal, Madrid, 2005, p 103. 
Decir que la memoria es una construcción que parte del presente, resultaría para muchos tal vez una obviedad. Sin embargo, más allá de esta obviedad, en este puente entre pasado, presente y futuro que la caracteriza, "lo comparativo" aparece como el elemento de referencia que une, a la vez que separa, a estos distintos espacios temporales. ${ }^{22}$ Hablar de la militancia de las generaciones actuales parecería implicar, o al menos de ese modo fue emergiendo en cada testimonio, la necesidad de volver sobre las prácticas militantes y los acontecimientos de la década del setenta. Al mismo tiempo, esta referencia permanente al pasado engloba no solo aquello que para un sujeto aconteció en términos de experiencia, sino también aquello que nunca llegó a suceder. En este sentido, desde la teoría analítica nos encontramos con algunos autores $^{23}$ que retoman los aportes de Reinhart Koselleck para el estudio de los procesos y cambios históricos. Nos referimos a las categorías de "espacio de experiencias" y "horizonte de expectativas". La categoría de "espacio de experiencias" se define por la incorporación de acontecimientos que son recordados: un día de militancia en Ingeniero White, los sucesos de Ezeiza con la concentración en la UOCRA de Bahía Blanca, la campaña de afiliación de Héctor Cámpora y la presencia del mismo en el estadio de Villa Mitre, entre muchos otros. Mientras que la de "horizonte de expectativas" refiere a lo no experimentado. Lo que no sucedió, pero que aún puede descubrirse, la continuidad y profundización de un proyecto político, por ejemplo, anclado en el presente. Acontecimientos que, de acuerdo con las edades y determinados posicionamientos, son asimilados por los sujetos como experiencias, constituyéndose por tanto en "núcleos de sentido". Estos núcleos de sentido son los que definen y designan, siguiendo a Mudrovcic, ${ }^{24}$ a una generación. Destacamos estos planteos, en tanto uno de los fines analíticos propuestos, se centró en cómo en el presente histórico se reactualizan, en términos de continuidad y discontinuidad, muchas características o hechos (políticos) del pasado respecto del modelo y de la práctica política que va desde el 2004 hasta el 2014. Procuraremos entonces, a continuación, dar cuenta de aquellos elementos que entran en tensión acerca de la militancia política y de las distintas interpretaciones a través de las cuales es pensada y resignificada la práctica política pasada, los paréntesis, los cambios, la construcción política, el pasado y el presente.

\footnotetext{
22 GONZÁLEZ, Gabriela Transformaciones de sentido de la práctica política. Prácticas y concepciones de "viejas y nuevas juventudes" en el devenir histórico, Tesis doctoral, Universidad Nacional de Rosario, 2014.

${ }^{23}$ Entre otros, CARNOVALE, Vera; LORENZ, Federico y PITTALUGA, Roberto (comps.) Historia, memoria..., cit. MUDROVCIC, María Inés Pasados en conflicto. Representación, mito y memoria, Prometeo, Buenos Aires, 2009. OBERTI, Alejandra y Roberto PITTALUGA Memorias en montaje, El Cielo por Asalto, Buenos Aires, 2006.

${ }^{24}$ MUDROVCIC, María Inés Historia..., cit.
} 


\section{Más-que-presente}

En uno de los pasajes en la introducción a su libro Ante el tiempo, DidiHuberman ${ }^{25}$ citaba una frase de Octavio Mannoni con el fin de adentrarse en la explicación de la existencia, en la historia, de un tiempo para el anacronismo. Según Mannoni, el anacronismo resultaría inevitable, siendo imposible interpretar el pasado prescindiendo de nuestro propio presente. Parafraseando esta frase de Mannoni, podría también decirse que tampoco es posible interpretar el presente sin recurrir para ello a nuestro pasado. En ambos casos se trataría de relaciones críticas que, a través de su enunciación presente, articulan un tiempo con el otro sin dejar por supuesto de lado el horizonte de expectativas futuras. ${ }^{26}$ De allí el título "más-que-presente" de este apartado, en tanto expresión de la inevitable vinculación entre estos distintos momentos con que permanentemente nos fuéramos encontrando a lo largo de cada testimonio. En este sentido, el presente se encuentra, la más de las veces, caracterizado por lo que algunos sujetos definen como un "rescate de la política", en relación a los gobiernos de Néstor Kirchner y Cristina Fernández. Un rescate que rememora viejos anhelos, recuperando así muchos objetivos generacionales pretéritos y poniendo en valor aquella militancia pasada. Quisiéramos ahora profundizar aún más en las reflexiones presentes acerca del presente, las cuales suscitan la experiencia pasada y las características en torno al rescate de la política recién mencionadas. Al mismo tiempo, estas reflexiones evidencian cómo en la reconstrucción de las memorias de aquellos sujetos que en su juventud militaran en el marco del peronismo de Bahía Blanca aparecen recuerdos e interpretaciones heterogéneas, incluso sobre los mismos hechos o análisis.

A lo largo de los testimonios y de gran parte del imaginario social acerca de Bahía Blanca, la ciudad suele ser caracterizada, tal como párrafos más arriba mencionáramos, en torno de los vínculos estrechos entre la sociedad bahiense y las Fuerzas Armadas. Esta afirmación parecería contradictoria respecto de aquella que enfatiza en el lugar que la política ocupa hoy en nuestro país, no solo en términos una militancia de corte más político. Más aún cuando frecuentemente en ese mismo imaginario, e incluso en los testimonios recogidos, se alude a "las manifestaciones bahienses de la clase media" y su permanente "'no te metas" y "lo sucio de la política". También sobresalen interpretaciones que refieren a la "idiosincrasia oligarca" que caracterizaría a la ciudad, siempre en relación con el aparato ideológico de La Nueva Provincia.

En este punto las memorias presentes devienen un tanto ambiguas, en la medida en que a esa ciudad a la que muchos definen como "gorila y reaccionaria", se le contrapone otra que rescata lo que fuera la Resistencia

\footnotetext{
${ }^{25}$ DIDI-HUBERMAN, George Ante el tiempo, Adriana Hidalgo, Buenos Aires, 2006.

${ }^{26}$ MUDROVCIC, María Inés Historia..., cit.
} 
Peronista bahiense, las movilizaciones y actos gigantescos de la $\mathrm{JP}^{27}$ las actividades desarrolladas por las unidades básicas tras las elecciones presidenciales de 1973, etc. $\operatorname{Marcos}^{28}$ nos advertía, en el transcurso de una entrevista, acerca de las implicancias de esta caracterización de la sociedad bahiense como gorila y reaccionaria, dado que la misma, agregamos, contribuye tanto a invisibilizar las memorias sobre un pasado que merece que aquellas experiencias sean valorizadas a la luz de los interrogantes presentes, como a generar determinadas estigmatizaciones que bien pueden obturar los procesos actuales de memorialización.

El incremento en la participación sindical en los últimos años, la posibilidad de presentar listas kirchneristas para las elecciones locales, la apertura de nuevos espacios de participación política y de derechos humanos inexistentes durante las décadas anteriores, la presencia de otros medios de comunicación que pudieron captar algunos de los lectores de la todavía hegemónica Nueva Provincia y la reestructuración que sufrieran las Fuerzas Armadas, forman parte de los acontecimientos o reflexiones expresadas en este sentido y que, al mismo tiempo, pudimos observar en la ciudad de Bahía Blanca. Para Javier ${ }^{29}$, por ejemplo, se trata de un "milagro del kirchnerismo" el hecho de que la experiencia actual les va a llevar, a las Fuerzas Armadas, "a ser más prudentes y que se empiece a hablar de La Nueva Provincia". Carlos ${ }^{30}$ también plantea en términos de "milagro" las transformaciones que tuvieron lugar en este sentido, metáfora que, según él, representa

"un logro cualitativamente importantísimo, es decir, el hecho de que con todas las idas y vueltas, con todos los carapintadas y con todas las oposiciones de diputados, de senadores, de la justicia, de los políticos, pero se fue logrando el estado este por el cual la sociedad en general legitima las grandes banderas y abjura a los dictadores y se hizo carne y conciencia colectiva todo esto. Ese tránsito fue fundamental y eso es lo más aglutinador y lo más

\footnotetext{
${ }^{27}$ Del análisis de fuentes escritas como el diario $E l$ Eco nos encontramos con una serie de notas que hacen mención a la realización de diversos actos de gran concurrencia, los cuales tienen lugar con la campaña electoral de Cámpora-Solano Lima. Entre tales notas se destaca una en particular titulada bajo el nombre de Gigantesco acto de la JP, en la que se destaca la presencia de entre 14 y 15 mil asistentes, tanto de Bahía Blanca como de delegaciones de la zona, de Capital Federal, Viedma, Ensenada, entre otras (El Eco, Bahía Blanca, 06 de marzo de 1973, p. 3).

${ }_{28}$ Marcos es ingeniero y vive en México. En los setenta se incorporó a la JUP (Juventud Universitaria Peronista) bahiense a través de uno de sus referentes, Heber Tapattá. Entrevista realizada en agosto de 2013.

${ }^{29}$ Javier actualmente es uno de los referentes del Partido de la Victoria de Bahía Blanca. En los setenta militó en el Peronismo de Base. Entrevista realizada en julio de 2013.

${ }^{30}$ Carlos vive en Capital Federal..., cit.
} 
cualitativamente importante de esta construcción que surge en la nueva generación."

De todos modos, algo de lo viejo siempre parece circular por algunos canales en los que encuentra espacios. Así lo recuerda Marcelo ${ }^{31}$ a modo de anécdota sobre la continuidad en el posicionamiento ideológico-político de $\mathrm{La}$ Nueva Provincia, en tanto "único medio que le hizo la despedida formal a Massera" o ante el retiro de Vilas (en relación a Acdel Vilas ${ }^{32}$ ) por medio de una editorial de La Nueva Provincia con el título “¿Quién nos defiende ahora?”. También Dora ${ }^{33}$ detalla un acontecimiento que se orientaba a la idea de cierta continuidad, cuando -aún alarmada- narraba la experiencia que ella y Ricardo ${ }^{34}$ vivieron al momento en que parte del personal de la Escuela de Mecánica de la Armada (ESMA) se trasladó a la Base Naval Puerto Belgrano. En esa oportunidad el entonces presidente Néstor Kirchner asistiría a la inauguración de la ESOA (Escuela de Suboficiales de la Armada) en noviembre de 2006. Dora recuerda como en el transcurso de su discurso, Néstor Kirchner

"habló de la pesada mochila que llevan [las Fuerzas Armadas], que tienen que reivindicarse con la sociedad, con una educación nueva, más abierta, más comprensible hacia el ser humano y que 'poco a poco, van a ir descargando esa mochila tan pesada que llevan de tantos años de matar a sus propios hermanos, los propios argentinos'."

Tras el discurso -continuó Dora- "sale el comandante y les dice algunas palabras, eran, no sé, mil y pico de cadetes, todos vestidos de blanco, todos con armas y le dan una orden y se arrodillan y tiran balas de fogueo hacia el palco". La escena resulta por demás significativa, al tiempo que evoca la preocupación de Griselda ${ }^{35}$ respecto a la facilidad con que muchos represores se fugan gracias a sus contactos, aún vigentes, dentro de las Fuerzas Armadas. Entre los casos más conocidos se encuentra el de Julián Oscar "Laucha" Corres. ${ }^{36}$ Lo destacable de su preocupación es el vínculo vigente que muchos represores y civiles, como Vicente Massot, dueño de La Nueva Provincia, aún continúan manteniendo con otros miembros de las Fuerzas Armadas y el Poder Judicial. Familiaridad que, por otra parte, nos devuelve aquella imagen de ciudad vigilada ya aludida.

\footnotetext{
${ }^{31}$ Marcelo es docente..., cit.

${ }^{32}$ Luego de haber estado a cargo del Operativo Independencia en Tucumán en 1975, Vilas se desempeñó como segundo comandante del V Cuerpo de Ejército de Bahía Blanca.

${ }^{33}$ Dora es ama de casa y vive en Bahía Blanca. En los setenta participó como militante de Base de la JTP. Entrevista realizada en febrero de 2011.

${ }^{34}$ Ricardo es jubilado..., cit.

${ }^{35}$ Griselda es docente y miembro del Mo.Ve.Ju.Pa. Vive en la ciudad de Punta Alta. Registro julio de 2012.

${ }^{36}$ El teniente coronel Julián Oscar Corres fue uno de los represores del centro clandestino de detención conocido como "La Escuelita", que funcionó en las dependencias del V Cuerpo de Ejército de Bahía Blanca.
} 
Ahora bien, no todos los relatos coinciden en sus apreciaciones respecto del actual papel de las Fuerzas Armadas. En este sentido, Javier ${ }^{37}$ plantea que hoy "los milicos están muy cascoteados"; mientras que Ricardo ${ }^{38}$ también $^{2}$ coincide con esta postura, dado "el retroceso de los militares que aparentemente es para siempre". Profundizando aún más en esta idea de retroceso de los militares, Marcelo ${ }^{39}$ consecuentemente se pregunta por el nuevo lugar de las Fuerzas Armadas en la actualidad.

"En aquel tiempo los que eran militares pensaban que podían gobernar. Hoy creo que esta idea mesiánica ya se les ha quitado. De a poquitito habrá que hacerlos entrar en el orden constitucional y que dentro de un orden constitucional ellos tienen que estar para otras acciones que no sean las de derrotar gobiernos y las de pensarse de que pueden gobernar. Esto también va constituyendo nuevos sujetos que dicen que el rol de las Fuerzas Armadas es la defensa, tratar siempre de estar cuidando las fronteras."

A este respecto, las resistencias y las transformaciones de las Fuerzas Armadas en la actualidad suelen expresarse en muchos de los testimonios en términos de preocupación sobre "lo que se puede perder si volvemos atrás" (Javier). Un volver atrás ya no en el sentido de la posibilidad de un nuevo golpe de Estado, sino más bien de un retroceso hacia las políticas neoliberales del noventa. En este punto es donde la militancia de las nuevas generaciones juega un papel fundamental. Una militancia a la cual se la evoca, la más de las veces, desde las continuidades y discontinuidades respecto de la denominada generación del setenta.

\section{Sentidos sobre la militancia política de las generaciones presentes}

La militancia de las nuevas generaciones suscita, siguiendo los testimonios recogidos, posturas en las que subyace desde la nostalgia por los "viejos tiempos" hasta el recelo e, incluso, la desaprobación de algunas de sus prácticas $\mathrm{u}$ objetivos perseguidos. En este abanico de miradas, sin embargo, la transmisión "generacional" juega un papel significativo en términos del potencial que esta conlleva, ya para religar pasado, presente y futuro, ya para obturar determinados procesos políticos presentes. De esta manera, nos encontramos con algunos testimonios en los que la recurrencia a los jóvenes, a las "nuevas generaciones" -con el peso que lo generacional posee para los sujetos que nos brindaron su testimonio-, a ciertas estéticas militantes reproducidas, al rescate de determinados símbolos propios de la política, etc.,

\footnotetext{
${ }^{37}$ Javier actualmente es uno de los referentes..., cit.

${ }^{38}$ Ricardo es jubilado..., cit.

${ }^{39}$ Marcelo es docente..., cit.
} 
son destacadas con mayor énfasis. Por otro lado, están quienes, más allá del reconocimiento por la participación política que esas "nuevas juventudes" vienen sosteniendo, centran más su mirada en lo que consideran distintas "faltas", como por ejemplo en lo que atañe a la formación política y/o ideológica. Si bien, la más de las veces, estos señalamientos conllevan una mirada crítica en función de determinados posicionamientos políticos, los mismos se realizan siempre desde el lugar de diferenciar las prácticas políticas de una y otras generaciones. Esto es, una comparación mediada por lo que se espera sea una transmisión lograda. ${ }^{40}$

En algunos testimonios, tal contraposición se presenta respecto de la relación entre quienes conducen y quienes militan en las bases. Dora ${ }^{41}$ daba cuenta de esta relación en lo que ella define como el "problema de dejarse llevar de las narices". Un problema que, dejando a un lado el tema de la lucha armada, asocia específicamente con lo acontecido entre la conducción de Montoneros y los militantes de los diferentes frentes de masa que estaban bajo la órbita de dicha organización. Para otros, en cambio, tal relación se expresa en el corte "carismático" que se le asigna a la militancia actual, centrado en la figura de Cristina Fernández. Más allá de las diferencias entre una y otras posturas, lo interesante de ambos planteos, aquí abordados muy sintéticamente, es cómo los mismos nos permiten entrever posicionamientos presentes respecto de lo que fuera la militancia pasada. Esto es, algunos de los conflictos más destacados que permearon la militancia en la década del setenta. A saber, las disputas acerca del rol de las conducciones y las bases arriba aludido, es decir, las lecturas sobre la realidad que guían la práctica política en relación a quién/quiénes conducen al Movimiento y de qué forma lo hacen.

Frente a estas miradas, la formación politica y/o doctrinaria, parecería entonces adquirir un lugar privilegiado, en la medida en que se la considera no solo el punto de partida, sino además aquello que sostiene y otorga sentido a la práctica política, propiciando así salvar determinados escollos. Carlos ${ }^{42}$ señala, en este sentido, cómo el retomar las herencias políticas, en este caso del peronismo, implica la posibilidad de "retomar lo anterior, retomar a partir de este estado actual los mejores sueños de una sociedad". De ahí la importancia que por ejemplo tuvieran para la generación del setenta acontecimientos como el 17 de octubre y la Resistencia Peronista, entre otros. Mientras que en la actualidad la evocación a una juventud maravillosa, la plaza llena, las grandes movilizaciones de la década del setenta, etc., se han ido transformando en un punto de anclaje significativo.

\footnotetext{
40 TODOROV, Tzvetan Los abusos de la memoria, Paidós, Buenos Aires, 2000.

${ }^{41}$ Dora es ama de casa..., cit.

${ }^{42}$ Carlos vive en Capital Federal..., cit.
} 
A su vez, tales "herencias" se hallarían acompañadas de lo que para algunos constituye este "nuevo resurgimiento del Movimiento nacional" y de la puesta en la escena pública de lo que para el peronismo constituyen sus tres banderas fundamentales, a saber: la justicia social, la independencia económica y la soberanía política. Gran parte de la retórica actual, retomaría incluso mucho de su predecesora. Lo mismo ocurre con determinados símbolos visibles en la militancia, sobre todo en los distintos actos y movilizaciones en las que la juventud se constituye en el principal actor protagónico. Se trata de una continuidad de gran poder simbólico ejercido por medio de una ritualidad particular. Una ritualidad que, siguiendo a Smietniansky, ${ }^{43}$ permite sostener o reconfigurar determinadas relaciones de poder que van siendo tensionadas y rearticuladas de manera coyuntural. ${ }^{44}$

\section{Pasado, presente y futuro}

En la relación entre pasado, presente y futuro es posible hallar, entre muchos de los testimonios relevados, el temor ya no por la posibilidad de que se produzca un nuevo golpe de Estado, sino por un volver a "la no política", que es la que se asevera se restituye luego de varios años de haber estado "guardada en un cajón" (José). ${ }^{45}$ Algunos incluyen en estas afirmaciones, aunque sin profundizar en ello y de forma más solapada, al menemismo. Dicho temor aparecería representado, más que nada, en la posibilidad de un retorno a las políticas neoliberales de la década del noventa, con sus ya conocidas consecuencias: la exclusión, el hambre, el desempleo, las corporaciones delictivas y mafiosas, la falta de servicios como educación y salud pública, las privatizaciones, el cierre de numerosas industrias nacionales, entre otros, tal como es enfatizado en los distintos relatos.

$\mathrm{Si}$ "el problema fuera perder bancas en el parlamento, o no tener tal ministro -sostiene Marcos$^{46}{ }_{-}$, el problema terminaría ahí". Pero "el problema continúa- es que va a haber menos servicios sociales, se va a volver para atrás en salud pública, van a ser las cosas importantes las que vamos a perder. Se va a regresar al liberalismo o al neoliberalismo y a la mentira del desarrollo, o sea, a la exclusión de los pobres, de los trabajadores en general".

\footnotetext{
${ }^{43}$ SMIETNIANSKY, Silvina "El juicio de residencia: variabilidad y conflicto en el orden ritual (Gobernación del Tucumán, siglo XVIII)", en BOIBIN, Mauricio; HEREDIA, Beatriz de y ROSATO, Ana (comps.) Política, instituciones y gobierno: abordajes y perspectivas antropológicas sobre el hacer política, Antropofagia, Buenos Aires, 2009, pp. 229-256.

${ }^{44}$ GONZÁLEZ, Gabriela Transformaciones..., cit.

${ }^{45}$ José militaba hasta el 2013 en el gremio de Vialidad Nacional en Bahía Blanca, mientras que en los años setenta militó en la organización Montoneros. Entrevista realizada en julio de 2013.

${ }^{46}$ Marcos es ingeniero..., cit.
} 
En cuanto a esta destacada emergencia de "la política", la que se ubica tras la llegada al gobierno de Néstor Kirchner, la misma se encuentra acentuada a través de diversos sentidos que le otorgan un carácter positivo. Es decir, la importancia que su restitución conlleva para el conjunto de la sociedad, visible en "la reconstrucción del Estado, la autoridad política, la autoridad presidencial y la explosión militante luego del fallecimiento de Néstor Kirchner" (Javier) ${ }^{47}$ Cabe aclarar, de todos modos, que la incorporación de las nuevas generaciones a la militancia, la cual se sostiene se ha estructurado en torno a las memorias del pasado reciente, es al mismo tiempo concebida en términos de despertenencia respecto del pasado. Ambigüedad que hemos intentado destacar a lo largo de estas páginas en relación tanto a la militancia como a ciertos imaginarios en torno a la ciudad de Bahía Blanca.

Nuestra intención entonces, ha sido poder dar cuenta de las contradicciones emergentes como parte de los contextos histórico-políticos que atravesaron y atraviesan los testimonios acerca de la militancia pasada y presente. En este sentido es que procuramos ir y volver sobre los testimonios abordados, sobre aquello que los sujetos enuncian como parte de una reflexión presente en la que el pasado siempre emerge de manera significativa, tratando así de ubicar algunos indicios vinculados con nuestra problemática de investigación. Indicios que nacen de memorias movilizadas casi siempre por las pasiones que suscitan y que -según Marcelo ${ }^{48}$ - atravesaron a una generación. Pasiones que, por otro lado, conducen al resurgimiento de ciertas nostalgias por el pasado, pero también diversas miradas críticas en torno al destino político y de la política en nuestro país. Así lo expresan algunos testimonios:

“Esperemos que siga Cristina por lo menos. Pero hay que cambiar tantas cosas en esta Argentina que no sé si le va a alcanzar el tiempo. Teníamos la esperanza de Kirchner, bueno se fue el pingüino, pero ojalá que siga esta política y cambie un poco la mentalidad de la gente, que vuelva a ser la Argentina de antes, principalmente para los jóvenes, porque ahora es terrible cómo se están destruyendo" (Dora). ${ }^{49}$

"Poder lograr consolidar un gobierno democrático, yo creo que cada vez es más difícil para ellos [la oposición] poder cambiar esta política de independencia, de crecimiento, ni de revolución ni de nada, que ha generado un poco de justicia y que con el tiempo se puede avanzar en otras cosas, porque hasta ahora en lo que hemos avanzado es en

\footnotetext{
${ }^{47}$ Javier actualmente es uno de los referentes..., cit.

48 Marcelo es docente..., cit.

${ }^{49}$ Dora es ama de casa..., cit.
} 
desendeudarnos, en que haya producción, que haya mucha producción es bueno pero faltan muchas cosas, sin duda" (Ricardo). ${ }^{50}$

"Yo creo que el problema es que no sabemos formar cuadros, no hemos formado cuadros, tenemos que pedir cuadros prestados, se los pedimos a la UCD, técnicos, y se los pedimos al PC [...] tenés que consolidar una estructura, no una orga, ni 10 orgas, sí una estructura, una orgánica que te permita confiar, quién carajo va a ser el que suceda a Cristina" (Javier). ${ }^{51}$

Retomando lo hasta aquí plasmado, tanto en torno a las valoraciones y concepciones sobre el denominado "resurgimiento de la política", como a los sentidos que se hallan en relación a la presencia de las Fuerzas Armadas en Bahía Blanca, los temores ante la posibilidad de un vuelco hacia las políticas neoliberales de los noventa y la actual militancia de las nuevas generaciones con sus continuidades y discontinuidades respecto de la militancia de la década del setenta, consideramos que las diversas formas en que los sujetos se aproximan a nuestro pasado reciente y lo ponen en tensión con la actualidad deviene en clave fundamental de toda construcción política presente y futura.

Teniendo en cuenta que la construcción de la memoria conlleva, por ende, la transmisión de una narrativa atravesada por las experiencias pasadas y presentes y por las expectativas hacia el futuro, nuestra intención a lo largo de estas páginas ha sido dar cuenta de cómo un proceso histórico que para muchos comienza con "los días felices del peronismo" (Horacio) ${ }^{52}$ allá por la década del cuarenta, es resignificado en el presente, adquiriendo así una enorme potencialidad política. Lo medular de esta potencialidad, que a su vez atraviesa parte de las memorias de Bahía Blanca, sería entonces su capacidad transformadora, un acto que hace del pasado algo "más-que-pasado", parafraseando a Didi-Huberman, ${ }^{53}$ y del presente algo "más-que-presente". En otras palabras, se trataría de una trama de relaciones que nos permitan comprender de dónde venimos para saber hacia dónde podemos ir.

\footnotetext{
50 Ricardo es jubilado..., cit. Entrevista realizada en julio de 2013.

51 Javier actualmente es uno de los referentes..., cit.

${ }^{52}$ Horacio fue militante sindicalista en Luz y Fuerza durante la década del setenta y uno de los fundadores en 2011 del Mo.Ve.Ju.PA. Entrevista realizada en febrero de 2011.

${ }^{53}$ DIDI-HUBERMAN, George Ante el..., cit.
} 


\section{Consideraciones finales}

Un eje transversal de este trabajo ha sido la consideración de la experiencia singular del sujeto, en este caso en torno a su militancia pasada, como única e irrepetible. De allí el valor asignado al relato testimonial como herramienta, entre tantas otras, a partir de la cual aproximarnos al pasado reciente. Por otro lado, cabe destacar que en términos de lo que fuera la militancia durante la década del setenta, existen ciertas características que bien podemos encontrar en distintas ciudades del país, más aún cuando se trató de una práctica llevada a cabo a nivel nacional. En este sentido, si bien los procesos y prácticas políticas que tuvieron lugar en la ciudad de Bahía Blanca podrían ser representativos de otras localidades y viceversa, nuestro interés estuvo orientado, más que a "reconstruir" una historia común, hacia la visibilización de memorias de militancia en un contexto particular. Asimismo, la relación que estableciéramos entre tales militancias pasadas y las prácticas políticas desarrolladas durante los gobiernos kirchneristas, responde a la forma en que las memorias fueron emergiendo al momento de nuestro trabajo de campo. La recurrencia constante al kirchnerismo, a la "vuelta de la política" y al "retorno de la militancia" nos hablan entonces de memorias que se repreguntan por el pasado desde el acontecer presente del sujeto que las enuncia.

Focalizándonos entonces en las mismas, en este recorrido que fuéramos realizando a partir de algunos testimonios de ex militantes peronistas de la ciudad de Bahía Blanca, nos fuimos encontrando con una memoria a la que caracterizamos como ambigua. Una ambigüedad que se hace visible por medio de las diversas formas en que los sujetos se aproximan a lo acontecido, desde un ir y venir permanente entre el pasado y el presente, entre sus propias prácticas políticas, pero también respecto de las prácticas de las nuevas generaciones de militantes. El análisis realizado nos permitió además reflexionar acerca de determinadas continuidades y discontinuidades que los sujetos enunciaban respecto de la militancia presente, en comparación con sus propias trayectorias políticas.

La "valencia política" de la memoria giraría entonces sobre la posibilidad de retomar el pasado, o en este caso las experiencias de militancia pasadas, a la luz de los interrogantes y necesidades del presente. Ahora bien, todo movimiento en este sentido no podría escindirse del contexto histórico-político que, o bien lo habilita, o bien lo coarta. En este sentido, el auge que la memoria ha tenido durante los últimos años se inscribe dentro de esta posibilidad y deja abierta la pregunta por la potencialidad o despotencialidad que acarrea el hecho de que la misma haya formado parte de una política de Estado.

La cuestión de la "reapertura de la política" -tal como la definen los entrevistados- constituye, entre otros, un camino a través del cual se vertebran algunas de estas reflexiones. Respecto de los testimonios abordados, las 
interpretaciones acerca de lo que se consideraba como reapertura política asociaban esta "particularidad" con la revalorización que consideran que el kirchnerismo ha promovido de la política, en términos más generales. De todos modos, sostenemos que esta promoción de la política en relación exclusiva con la militancia no implicaría necesariamente el retorno de lo político. Se trata de un hecho tal vez más difuso al momento en que realizamos nuestro trabajo de campo, pero que ante la coyuntura actual se abre a nuevas interpretaciones y discusiones.

Por otro lado, la definición dada en los testimonios respecto a la destacada reapertura de la política, la misma se enuncia comúnmente en términos de milagro. Ello no significa que el trasfondo de dicha interpretación conlleve un principio o esencia de tipo religioso. Por medio de su empleo, en cambio pareciera querer enfatizarse lo ininteligible e inesperado de esta etapa política abierta en el 2004 y a la que muchos le adjudican ciertos paralelismos con los gobiernos peronistas de 1945 y de 1973. Sin embargo, esta idea de paralelismo no es subrayada en términos de homologación entre los gobiernos de Juan Domingo Perón y de Néstor Kirchner y Cristina Fernández. Las relaciones que los propios sujetos realizan, por consiguiente, darían cuenta tanto de las continuidades como de las singularidades propias de dichos gobiernos y -a partir de allí- de lo similar y de lo particular de las concepciones y prácticas políticas de cada época.

Ahora bien, más allá de estas coincidencias y diferencias entre una y otra etapa política, lo medular de este análisis respecto de las continuidades y discontinuidades entre el pasado y el presente es el tema de la transmisión intergeneracional. En este enfatizado "resurgimiento de la política", aparecían determinadas tensiones que para nosotros responderían a cómo el sujeto generacional de la década del setenta concibe la militancia de las generaciones más recientes y la práctica política en un sentido más abarcador. De esta manera nos fuimos encontrando con que la transmisión de las experiencias pasadas actuaba y actúa, ya como ideal o nostalgia de un tiempo pasado, ya como potencial transformador de la realidad, es decir, como algo "más-que-pasado",, 4 ya como eje doctrinario respecto de la juventud actual.

Entre las interpretaciones que ubicamos en términos de un idealismo o nostalgia, el pasado aparece representado como algo cristalizado, compacto, poco permeable a ser sometido a cualquier crítica; a la vez que no deja posibilidad alguna de superar lo acontecido o de establecer relaciones con el presente. En este caso se trataría de una transmisión de tipo literal, siguiendo a Todorov. ${ }^{55}$ Todo lo contrario sucedería con aquellas posturas que parten por el contrario de una crítica abierta, capaz de dar cuenta tanto de los aciertos, como

\footnotetext{
54 DIDI-HUBERMAN, George Ante el..., cit.

55 TODOROV, Tzvetan Los abusos..., cit.
} 
de los errores pasados para desde allí dar lugar a nuevas concepciones y prácticas en el presente, proyectando a su vez el futuro. Por último, están aquellas posturas cuyas miradas hacia la militancia de juventud actual es de cierto recelo. Aparece así -no siempre de manera explícita- una especie de desconfianza sobre la militancia presente, rodeada de un imaginario comparativo respecto de las implicancias de una militancia vivenciada en términos de una "entrega total". Al mismo tiempo, estas experiencias pasadas conllevan la idea del sustento ideológico y de la formación política como características primordiales de una generación, pero ausente en la otra. Certeza política que vincularía a la primera de dichas generaciones con la última, en términos de advertencia o de enseñanza, en un sentido más unidireccional.

Las diversas maneras en que la experiencia pasada procura ser puesta en movimiento en el presente -más allá de esta división taxativa que hiciéramos a los fines analíticos- se encuentra atravesada por matices, por las singularidades propias de cada sujeto y por el contexto de enunciación. Un contexto que por momentos se presenta de manera a-crítico y de enorme idealización de los gobiernos kirchneristas. Subrayamos, sin embargo, que toda transmisión posee además una enorme carga afectiva y apasionada en la que se trasluce esa indisolubilidad entre la vida y la militancia que subyacía en cada testimonio. "Sin sentir no hay historia que tenga emoción, relevancia, que mueva sensaciones", nos decía Esteban. ${ }^{56}$ En cada transmisión, más allá de ella, lo que se halla en juego no son solamente las experiencias personales sino el proyecto político por el cual esas experiencias personales se anudaron a una trama colectiva que para muchos habría resurgido con los gobiernos kirchneristas, aunque de diferente manera.

Más allá de los diversos modos en que cada uno pudo, privilegió o intentó aproximarse al pasado, el pasaje social de aquellas experiencias a las generaciones actuales continúa siendo un debate pendiente y necesario como aprendizaje en relación con el presente. Más aún, en tanto este trabajo se dio en un momento político que parecería de ruptura con el presente en que es publicado, habría que sumar a este análisis nuevos elementos que, incluso, hasta podrían redefinir muchas de las posturas aquí esbozadas $\mathrm{u}$ otorgar nuevos sentidos a lo acontecido. Solo en la medida en que puedan problematizarse tanto los aciertos como los errores y fracasos, consideramos que será posible comenzar a zanjar dicho debate. No así mientras se sostenga un relato de tipo heroico o idealizado.

Algunos aseveraban, como Dora, ${ }^{57}$ que la juventud actual tendrá que hacer su camino. La pregunta que entonces cabe es qué retomará de las experiencias pasadas en ese camino, qué desechará de las mismas y qué

\footnotetext{
56 Esteban es arquitecto..., cit.

${ }^{57}$ Dora es ama de casa..., cit. Entrevista realizada en julio de 2013.
} 
reinventará como una construcción política propia. De ahí la importancia asignada al proceso de construcción de las memorias -en este caso de una experiencia particular- y a su transmisión. Importancia signada por el temor manifiesto sobre una posible despolitización. Posicionamiento que, como previamente enunciáramos, se sustenta en la idea del retorno a la política y que ante la actual coyuntura merece ser al menos revisado.

En este sentido, quisiéramos remarcar que en los últimos años han tenido lugar numerosos acontecimientos que llevaron a visualizar lo acontecido en Bahía Blanca, reproduciendo viejas y nuevas tensiones en la sociedad en su conjunto. Viejas en cuanto a sus participaciones directas e indirectas y nuevas, respecto de las posibilidades de una construcción política actual y futura, capaz de superar determinados errores y antagonismos. Si bien tales hechos, como los juicios a represores y civiles que se han desarrollado en la ciudad, han corrido cierto velo sobre lo que fuera la militancia política durante la década del setenta, consideramos que aun así se halla latente el peligro de que la memoria sea reducida tan solo a un acto tribunalicio y conmemoraciones acerca del horror, relegando el proyecto político por el que se luchó. Del mismo modo, el proceso de estatización de la memoria ha producido determinados relatos $y$ memoria hegemónicas, invisibilizando o negando otras.

Fue en gran medida esta inquietud la que nos movilizó a continuar adentrándonos en las memorias acerca de la militancia política en Bahía Blanca. Una militancia a la que caracterizamos atravesada por la indisolubilidad entre la vida misma y la política, es decir, como una opción de vida, con la intensidad que tuvo para la denominada generación del setenta, tal como es explícita o implícitamente esbozada en cada uno de los testimonios presentados. De esta manera, consideramos que la resignificación de aquel pasado y la problematización de los silencios y los miedos que aún persisten, permitirá que los mismos puedan comenzar a transitar nuevos y fundamentalmente propios caminos. Debate en curso, respecto de cómo el sujeto político del presente se aproxima al pasado y a sus propias experiencias de militancia política, ya desde una mirada crítica (política), ya desde una mirada más idealizada que al mismo tiempo nos permita dar cuenta de en qué medida las condiciones actuales de apertura facilitan una u otra mirada. Esto es, retribuir el sentido político de lo acontecido a partir de una transmisión capaz de atestiguar, aún con sus propias contradicciones, que el pasado no es solo olvido, miedo, derrota y muerte o, por el contrario, relatos heroicos e idealizados. Esa es precisamente, la paradoja de las narrativas de las memorias de Bahía Blanca. Memorias que en lo más hondo nos muestran lo intenso y apasionado de aquel tiempo político, pero que es necesario llenar de sentidos actualizados desde la práctica presente. En este sentido, y dada la distancia entre nuestro trabajo de campo y el presente en que escribimos, consideramos que es factible plantear numerosos interrogantes acerca de cómo hoy esos mismos sujetos configuran la política y las prácticas de 
militancia durante los gobiernos kirchneristas e, incluso, la relación entre esta y los años setenta. Interrogantes que, por otro lado, exigen una mirada crítica que no pierda de vista los contextos particulares en los que cada interpretación es realizada.

Rosario, 8 de abril de 2016 